J. Sci. Univ. Kelaniya 10 (2015): 13-20

\title{
OPTICAL AND STRUCTURAL PROPERTIES OF SPIN COATED CADMIUM SULFIDE THIN FILMS
}

\section{D.M.C.U. DISSANAYAKE AND P. SAMARASEKARA*}

\section{Department of Physics, University of Peradeniya, Peradeniya, Sri Lanka.}

\begin{abstract}
Thin films of cadmium sulfide have been synthesized using the spin coating technique. Films were fabricated on inexpensive amorphous glass substrates at spin speeds of 1500, 2200 and $2400 \mathrm{rpm}$ for 30 seconds. Films were subsequently annealed at 200, 300 and $400{ }^{0} \mathrm{C}$ for one hour in air in order to crystallize the phase of CdS. Films were characterized using X-ray diffraction patterns (XRD) and UV-visible spectroscopy. According to XRD patterns, the phase of $\mathrm{CdS}$ was crystallized without any secondary phases. The particle size, dislocation density and strain were also estimated using XRD patterns. All the films indicate a strong orientation in (002) direction. The optical band gap was determined using UV absorption spectroscopy. Tauc model was employed to determine the optical band gap. According to our data, the optical band gap decreases with the particle size.
\end{abstract}

Keywords: CdS, XRD, optical band gap, particle size, Tauc model

DOI: http://dx.doi.org/10.4038/josuk.v\%vi\%i.7989

\section{INTRODUCTION}

$\mathrm{CdS}$ is one of the most important II-VI group semiconductors with a direct band gap of $2.42 \mathrm{eV}$. CdS thin films belong to the Chalcogenide family and there is an extensive research work carried out with CdS mainly due to its potential applications in solar cells, especially as a window material for $\mathrm{CdS} / \mathrm{CdTe}$ solar cells because of its suitable band gap and stability (Olopade et al., 2013). Also, CdS thin film is one of the important materials for applications in light emitting diodes, sensors, photoconductors, optical mass memories

\footnotetext{
* Corresponding author Email: pubudus@pdn.ac.lk
} 
and solar selective coatings (Olopade et al., 2013). Nanostructures have attracted a great interest in recent years because of their unique chemical, physical, optical, electrical and transport properties which are different from those of either the bulk materials or single atoms. Due to the vast surface area, all nanostructured materials possess a high surface energy and thus, are thermodynamically unstable or metastable. CdS nanoparticles are considered as a capable applicant for their applications in future opto-electronic devices, nanodevices and biological labeling due to availability of discrete energy levels, tunable band gap, size dependent chemical and physical properties, better chemical stability and easy preparation techniques.

There are many methods of fabricating CdS thin films. These include spray pyrolysis (Yadav et al., 2010), chemical bath deposition (Lisco et al., 2015), electro deposition (Takahashi et al., 2002), screen printing (Kumar et al., 2011), physical vapor deposition and sol-gel spin coating. Among various deposition methods, sol-gel spin coating technique is extensively studied as a matrix material method to produce nanocomposites because it gives a higher specific surface area, superior homogeneity and purity, better microstructural control of metallic particles, narrow pore size and uniform particle distribution. The main advantages of the sol-gel method are its simplicity, low cost and its ability to obtain uniform films with good adherence and reproducibility in a relatively shorter processing time at lower temperatures.

In addition to optical and electrical properties, magnetic properties of films are also important. CdS possesses some magnetic properties (Rasu et al., 2006). The Heisenberg Hamiltonian was used to describe the magnetic properties of ferromagnetic and ferrite films by us previously (Samarasekara, 2006, Samarasekara, 2006, Samarasekara \& Silva, 2007). Thin films of Lithium mixed ferrite (Samarasekara, 2002), multi walled carbon nanotubes (Samarasekara, 2009), $\mathrm{Cu}_{2} \mathrm{O} / \mathrm{CuO}$ layers (Samarasekara, 2010), Nickel ferrite (Samarasekara, 2003) and copper oxide (Samarasekara \& Yapa, 2008) have been fabricated. Previously electrical properties of semiconductor particles doped with salts have been investigated by us (Tennakone et al., 1987). In this manuscript, the optical and structural properties of CdS films containing nano-particles will be described.

\section{EXPERIMENTAL}

For the deposition of $\mathrm{CdS}$ thin films two solutions have been prepared. Polyethylene Glycol (PEG) was dissolved in ethanol $\left(\mathrm{CH}_{3} \mathrm{CH}_{2} \mathrm{OH}\right)$, and acetic acid 
$\left(\mathrm{CH}_{3} \mathrm{COOH}\right)$ was added to ethanoic solution under stirring which was continued for 1 hour (Solution 1). Cadmium nitrate $\left(\mathrm{Cd}\left(\mathrm{NO}_{3}\right)_{2}\right)$ and thiourea $\left(\mathrm{CS}\left[\mathrm{NH}_{2}\right]_{2}\right)$ were dissolved in ethanol under stirring which was continued for 1 hour (Solution 2). Solution 2 was mixed with Solution 1 and stirred again for 4 hours to obtain the final sols for deposition of thin films. CdS thin films were deposited on ultrasonically cleaned glass substrates by sol-gel spin-coating technique. Solution was dropped onto the glass substrates at speeds of 1500 , 2200 and $2400 \mathrm{rpm}$ for 30 seconds. After deposition, the glass substrates were dried on hot plate at $120{ }^{\circ} \mathrm{C}$ for 1 hour and then annealed at temperatures of $200{ }^{\circ} \mathrm{C}, 300{ }^{\circ} \mathrm{C}$, and $400{ }^{\circ} \mathrm{C}$ in air for one hour.

Structural properties of film samples were determined using $\mathrm{X}$ ray diffraction (XRD) with $\mathrm{Cu}-\mathrm{K}_{\alpha}$ radiation of wavelength $1.54060 \AA$. UV-visible spectrometer was employed to investigate optical properties of samples.

\section{RESULTS AND DISCUSSION}

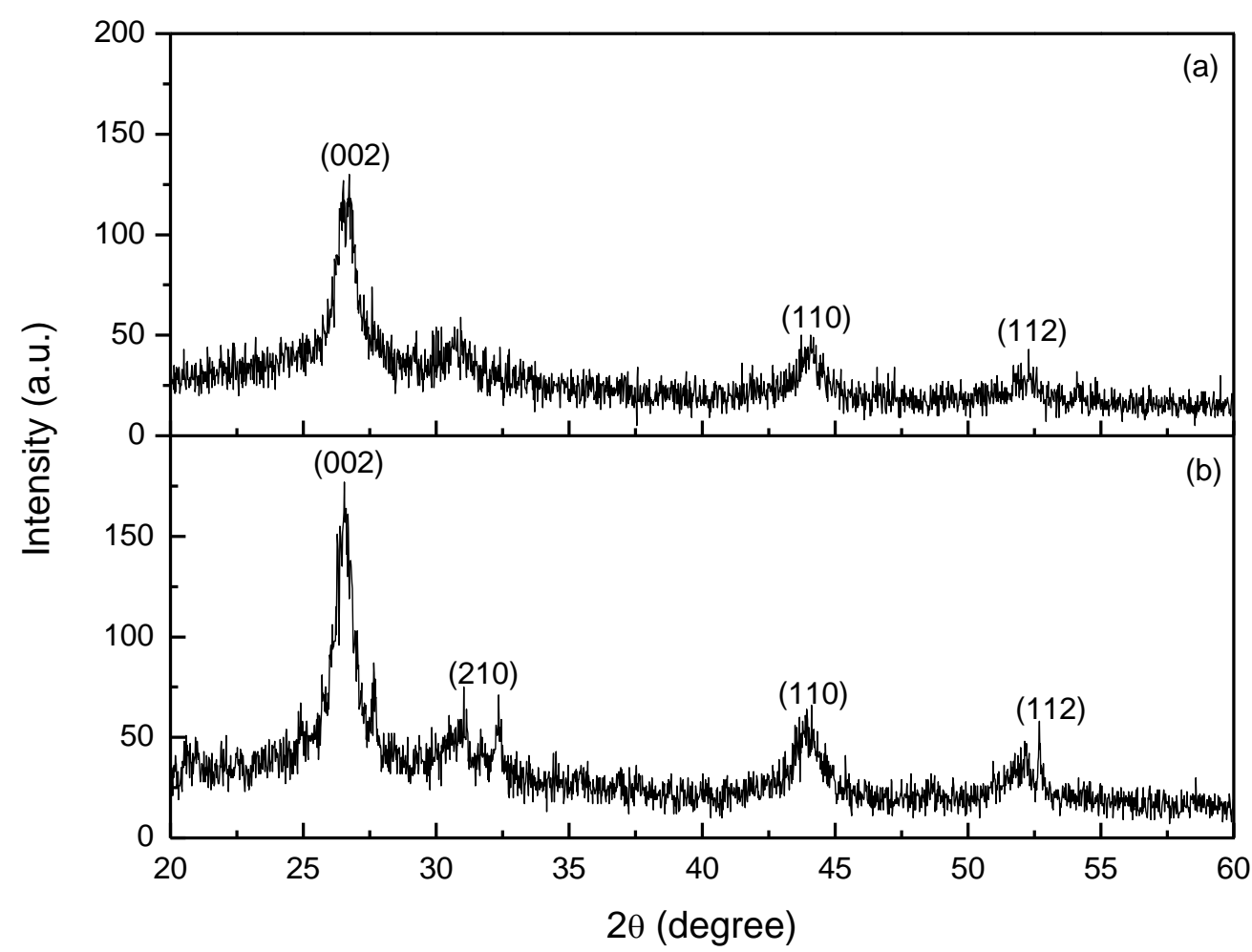

Figure 1: XRD of CdS thin films annealed at (a) $200{ }^{\circ} \mathrm{C}$ and (b) $400{ }^{\circ} \mathrm{C}$ coated at $2200 \mathrm{rpm}$ 
Figure 1 shows the XRD patterns of CdS films spin coated at $2200 \mathrm{rpm}$ and annealed at 200 and $400{ }^{\circ} \mathrm{C}$. The relationship between diffraction angle and the distance between parallel atomic planes (d) is given by the Bragg's law $2 \mathrm{~d} \sin \theta=m \lambda$, where $\theta$ is the Bragg angle, $\mathrm{m}$ is an integer equals to one, and $\lambda$ is the wavelength of the incident X-ray beam. The crystallite size (D) of the films is estimated using the Debye-Scherrer formula (Rathinamala et al., 2014) $D=\frac{0.91 \lambda}{\beta \cos \theta}$, where $\lambda$ is the $\mathrm{X}$-ray wavelength $\left(\mathrm{CuK}_{\alpha}=1.54060 \AA\right), \beta$ is the full width at half maximum (FWHM) of the dominant peak and $\theta$ is the Bragg angle. The dislocation density $(\delta)$ and strain $(\varepsilon)$ of $\mathrm{CdS}$ nanostructures were determined using these XRD results and following relations, respectively. $\delta=\frac{1}{D^{2}}$ and $\varepsilon=\frac{\beta \cos \theta}{4}$. In addition, the lattice parameters $a$ and $c$ were calculated by following relations, respectively. $a=\frac{\lambda}{\sqrt{3} \sin \theta}$ and $c=\frac{\lambda}{\sin \theta}$.

Table 1: XRD results of CdS thin films spin coated at $2200 \mathrm{rpm}$ and annealed at different temperatures

\begin{tabular}{|c|c|c|c|c|c|c|c|}
\hline 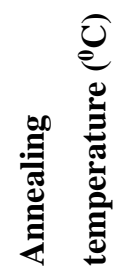 & 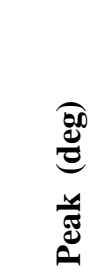 & 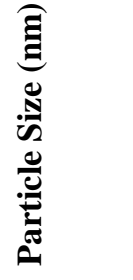 & 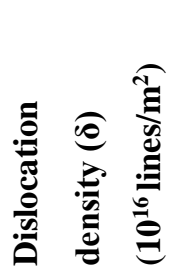 & 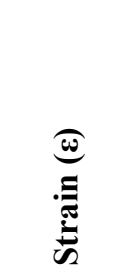 & 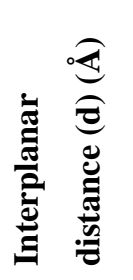 & 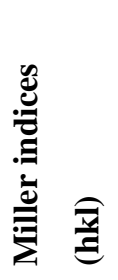 & 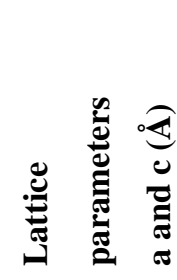 \\
\hline \multirow{3}{*}{200} & 26.62 & 6.09 & 2.70 & 0.0304 & 3.34 & (002) & $\begin{array}{l}\mathrm{a}=0.8861 \\
\mathrm{c}=1.5464\end{array}$ \\
\hline & 44.03 & 3.31 & 9.13 & 0.1680 & 2.05 & (110) & $\begin{array}{l}\mathrm{a}=0.0473 \\
\mathrm{c}=28.9503\end{array}$ \\
\hline & 52.32 & 6.42 & 2.43 & 0.1676 & 1.75 & (112) & $\begin{array}{l}a=0.7874 \\
c=1.7402\end{array}$ \\
\hline \multirow{2}{*}{300} & 26.56 & 9.00 & 1.23 & 0.3424 & 3.35 & (002) & $\begin{array}{l}\mathrm{a}=0.8802 \\
\mathrm{c}=1.5568\end{array}$ \\
\hline & 43.90 & 5.00 & 4.00 & 0.4459 & 2.06 & (110) & $\begin{array}{l}\mathrm{a}=0.0725 \\
\mathrm{c}=18.8889\end{array}$ \\
\hline \multirow{4}{*}{400} & 26.54 & 10.85 & 0.85 & 0.0323 & 3.36 & (002) & $\begin{array}{l}\mathrm{a}=0.8773 \\
\mathrm{c}=1.5619\end{array}$ \\
\hline & 31.15 & 5.82 & 2.95 & 0.3577 & 2.87 & (210) & $\begin{array}{l}\mathrm{a}=0.2308 \\
\mathrm{c}=5.9370\end{array}$ \\
\hline & 43.95 & 6.53 & 2.34 & 0.3427 & 2.06 & (110) & $\begin{array}{l}\mathrm{a}=0.0298 \\
\mathrm{c}=45.9554\end{array}$ \\
\hline & 52.06 & 6.48 & 2.38 & 0.0776 & 1.76 & (112) & $\begin{array}{l}a=0.8681 \\
c=1.5785\end{array}$ \\
\hline
\end{tabular}


Table 1 shows the values of particle size, dislocation density, strain and interplanar distance calculated using XRD patterns given in figure 1 for different XRD peaks. Calculated results shows that the crystallites of the CdS thin films were larger at higher temperatures.

The absorbance of film samples versus wavelength was measured using UV-visible spectroscopy. Hence the absorption coefficient at different wavelengths was calculated. Figure 2 indicates the graph of $(\alpha \mathrm{hv})^{2}$ versus (hv) for CdS thin film coated at $2200 \mathrm{rpm}$ and annealed at $300^{\circ} \mathrm{C}$. The optical band gap $\left(\mathrm{E}_{\mathrm{g}}\right)$ was determined using Tauc model by plotting $(\alpha \mathrm{hv})^{2}$ versus $(\mathrm{hv})$ and selecting the linear part in the relation of $(\alpha \mathrm{hv})^{1 / n}=\mathrm{A}\left(\mathrm{hv}-\mathrm{E}_{\mathrm{g}}\right)$. Here $\mathrm{A}$ is a constant, $\alpha$ absorption coefficient, hv the photon energy and $\mathrm{n}$ is equal to 2 for direct transitions.

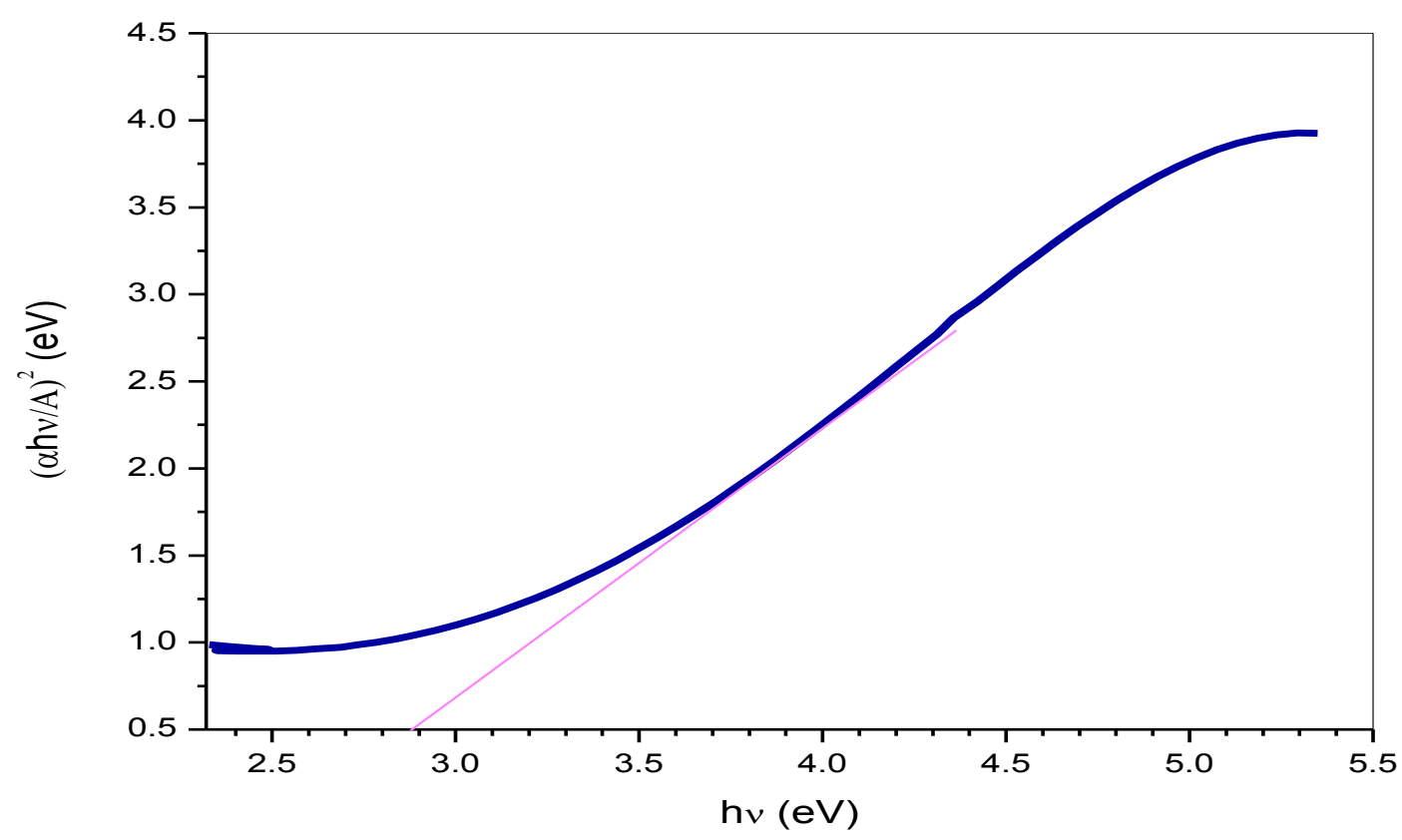

Figure 2: $(\alpha h v)^{2}$ versus (hv) plot of CdS thin film coated at $2200 \mathrm{rpm}$ and annealed at $300^{\circ} \mathrm{C}$

The calculated band gap values are greater than that of the bulk CdS as shown in Table 2. The optical energy gap decreases with increasing temperature and it indicates a slight increase with increasing spin speed. This indicates the formation of nanoparticles of $\mathrm{CdS}$ and quantum confinement effect. 
Table 2: Optical band gaps of CdS thin films spin coated at different spin speeds and annealed at different temperatures

\begin{tabular}{|c|c|c|c|}
\hline $\begin{array}{c}\text { Annealing } \\
\text { Temperature } \\
\left({ }^{\mathbf{0}} \mathbf{C}\right)\end{array}$ & \multicolumn{3}{|c|}{ Band gap(eV) } \\
\cline { 2 - 4 } & $\mathbf{1 5 0 0}$ & $\mathbf{2 2 0 0}$ & $\mathbf{2 4 0 0}$ \\
$\mathbf{r p m}$ & $\mathbf{r p m}$ & $\mathbf{r p m}$ \\
\hline 200 & 3.061 & 3.063 & 3.065 \\
\hline 300 & 2.885 & 2.886 & 2.887 \\
\hline 400 & 2.752 & 2.753 & 2.753 \\
\hline
\end{tabular}

The relation between particle radius and the band gap is given by Brus equation as follows.

$$
E_{g}=E_{b u l k}+\frac{h^{2}}{8 r^{2}}\left(1 / m * m_{e}+1 / m * h\right)-\frac{1.786 e^{2}}{4 \pi \varepsilon_{0} \varepsilon_{r} r^{2}}
$$

Where $E_{g}$ and $E_{b u l k}$ are the band gaps of CdS thin film and bulk, respectively, $h$ is the Planck's constant, $\mathrm{m}^{*} \mathrm{e}$ and $\mathrm{m}^{*} \mathrm{~h}$ are the effective masses of electron and hole, respectively, $\varepsilon$ is the dielectric constant and $r$ is the radius of the grains. The third term stands for the columbic interaction energy and often can be neglected due to high dielectric constant of semiconductor materials. Second term represents the additional energy due to quantum confinement having $\mathrm{r}^{-2}$ dependence on the band gap energy. If the sphere is too small, the movements of the electron and hole are restricted and so they feel confined which raises the energy required to excite the electron into the conduction band.

\section{CONCLUSIONS}

CdS nanostructures have been successfully prepared by the sol-gel spin coating method. Compared to the powder diffraction pattern of CdS, (002) peak of XRD pattern of our CdS film becomes dominant. All CdS thin films exhibit a favored direction along (002), and crystalline size increases with the annealing temperature. However, the dislocation density gradually decreases with the annealing temperature. This is related to the fact that the dislocation density decreases with the improvement of crystallization. The 
strain initially increases and then decreases with the annealing temperature. Lower strains can be observed at lower and higher annealing temperatures. Higher strains were observed at intermediate annealing temperatures. Strain mostly takes place in the film sample when the sample is cooled from annealing temperature to the room temperature. Due to that reason, when the sample is cooled from a lower annealing temperature to the room temperature, the strain is not that high. On the other hand, the strain will be lower at higher annealing temperatures due to the improvement of crystallization. In other words, because the particles are compact at higher annealing temperatures, any free space (or voids) required for strain is not available. The absorption studies revealed a strong blue shift indicating the presence of quantum confinement effect. As a matter of fact, the optical band gap decreases when the particle size increases. Furthermore, CdS nanostructures prepared at this range of annealing temperatures and spin coating speeds can be recommended for photovoltaic and optoelectronic applications.

\section{REFERENCES}

Kumar V., Sharma D.K., Bansal M.K., Dwivedi D.K. and Sharma T.P., 2011. Synthesis and characterization of screen printed CdS films. Science of sintering 43(3), 335-341. http://dx.doi.org/10.2298/SOS1103335K

Lisco P., Kaminski P.M., Abbas A., Bass K., Bowers J.W., Claudio G., Losurdo M. and Walls J.M., 2015. The structural properties of CdS deposited by chemical bath deposition and pulsed direct current magnetron sputtering. Thin solid films 582, 323-327.

http://dx.doi.org/10.1016/j.tsf.2014.11.062

Olopade M.A., Awobode A.M., Awe O.E. and Imalerio T.I., 2013. Structural and optical characterization of sol-gel spin- coated nanocrystalline CdS thin film. International Journal of Research and Reviews in Applied Sciences 15(1), 120-124.

Rathinamala I., Pandiarajan J., Jeyakumaran N. and Prithivikumaran N., 2014. Synthesis and physical properties of nanocrystalline $\mathrm{CdS}$ thin films- Influence of sol aging time and annealing temperature. International Journal of Thin Films Science and Technology 3(3), 113-120. http://dx.doi.org/10.12785/ijtfst/030306

Samarasekara P., 2002. Easy Axis Oriented Lithium Mixed Ferrite Films Deposited by the PLD Method. Chinese Journal of Physics 40(6), 631-636.

Samarasekara P., 2003. A Pulsed RF Sputtering Method for Obtaining Higher Deposition Rates. Chinese Journal of Physics 41(1), 70-74.

Samarasekara P., 2006. A solution of the Heisenberg Hamiltonian for oriented thick ferromagnetic films. Chinese Journal of Physics 44(5), 377-386.

Samarasekara P., 2007. Classical Heisenberg Hamiltonian solution of oriented spinel ferrimagnetic thin films. Electronic Journal of Theoretical Physics 4(15), 187-200. 
Samarasekara P. and De Silva S.N.P., 2007. Heisenberg Hamiltonian solution of thick ferromagnetic films with second order perturbation. Chinese Journal of Physics 45(2-I), 142150 .

Samarasekara P. and Yapa N.U.S., 2008. Effect of sputtering conditions on the gas sensitivity of Copper Oxide thin films. Sri Lankan Journal of Physics 8, 21-27. http://dx.doi.org/10.4038/sljp.v8i0.210

Samarasekara P., 2009. Hydrogen and Methane Gas Sensors Synthesis of Multi-Walled Carbon Nanotubes. Chinese Journal of Physics 47(3), 361-369.

Samarasekara P., 2010. Characterization of Low Cost $\mathrm{p}-\mathrm{Cu}_{2} \mathrm{O} / \mathrm{n}-\mathrm{CuO}$ Junction. Georgian Electronic Scientific Journals: Physics 2(4), 3-8.

Takahashi M., Hasegawa S., Watanabe M., Miyuki T., Ikeda S. and Iida K., 2002. Preparation of CdS thin films by electrodeposition: effect of colloidal sulfur particle stability on film composition. Journal of applied electrochemistry 32, 359-367. http://dx.doi.org/10.1023/A:1016325211708

Tennakone K., Wickramanayake S.W.M.S., Samarasekara P. and Fernando C.A.N., 1987. Doping of Semiconductor Particles with Salts. Physica Status Solidi (a)104, K57. http://dx.doi.org/10.1002/pssa.2211040148

Yadav A.A., Barote M.A. and Masumdar E.U., 2010. Studies on nanocrystalline cadmium sulphide (CdS) thin films deposited by spray pyrolysis. Solid state sciences 12(7), 1173-1177. http://dx.doi.org/10.1016/j.solidstatesciences.2010.04.001

Zhao X.G., Chu J.H. and Tang Z., 2015. Magnetic properties, Heisenberg exchange interaction and Curie temperature of CdS nanoclusters. The Journal of physical chemistry 119(52), 2907129075. http://dx.doi.org/10.1021/acs.jpcc.5b11037 